\title{
EL LÈXIC POPULAR VALENCIÀ \\ EN LA LITERATURA DE LES PRIMERES \\ DÈCADES DEL SEGLE XX: L'APORTACIÓ DE \\ FAUST HERNÁNDEZ CASAJUANA
}

\section{THE POPULAR VALENCIAN VOCABULARY IN THE LITERA- TURE OF THE FIRST DECADES OF THE 20TH CENTURY: THE CONTRIBUTION OF FAUST HERNÁNDEZ CASAJUANA}

\author{
Joaquim Martí Mestre \\ Universitat de València \\ joaquin.marti@uv.es
}

Resum: Hernández Casajuana va saber recollir en les seues obres literàries un interessant vocabulari popular, que en part enllaça amb la tradició lingüística dels dramaturgs valencians del segle XIX, i en part representa una innovació, des del moment que té en compte els canvis socials i de costums que es produeixen al segle xx, els quals tenen un reflex en el llenguatge. Aquest article se centra en aquesta parcel.la lèxica més innovadora d'Hernández Casajuana, tot i que considera també la producció d'altres autors contemporanis i anteriors. Així, proporciona novetats en relació amb els diccionaris històrics i etimològics, i dóna compte de la motivació i l'origen de determinats mots i accepcions, així com de diversos neologismes, en la seua etapa d'introducció en el català. Algunes d'aquestes innovacions lèxiques han desaparegut en la llengua actual, i altres han tingut continuïtat, però a principis del s. xx, quan encara no s'havien consolidat, presentaven a vegades formes diferents a les que han acabat triomfant.

Paraules clau: història del lèxic, llengua literària dels segles XIx i xx, lèxic popular, neologismes, Hernández Casajuana.

Abstract: In his literary works, Hernández Casajuana used an interesting popular vocabulary, which in part connects with the linguistic tradition of 19 th century Valencian playwrights, and in part represents an innovation, as it takes into account the social change and new customs arising in the 2oth century, and which were reflected in the language. The article deals with Hernández Casajuana's more innovative lexicon, though it also considers the work of other contemporary and earlier authors. It provides new ideas in relation to historical and etymological dictionaries and explains the motivation and origin of certain words and meanings; it also shows the presence 
of several neologisms at the time when they were being introduced into the Catalan language. Some of these new words have disappeared in today's language, while others continue, but at the beginning of the 2oth century, when they were as yet unconsolidated, they sometimes had different forms from those that have eventually prevail.

Key words: history of the lexicon, 19th and 20th century literary language, popular vocabulary, neologisms, Hernández Casajuana.

\section{escos es}

\section{UN ESCRIPTOR COSTUMISTA}

Faust Hernández Casajuana (I888-I972) és un dels dramaturgs valencians més interessants de la primera meitat del segle xx. Té catalogades cent trenta-sis obres dramàtiques, a més és autor d'algunes novel.les curtes i d'explicacions falleres, i va participar com a redactor en diverses revistes culturals i literàries del primer terç del segle. La major part de la seua producció, en efecte, se centra en els anys anteriors a la Guerra Civil, si bé després, i malgrat les dificultats per a la publicació de textos en català, no va abandonar mai l'activitat creativa. ${ }^{1}$

Excel-lent observador de la realitat social local del seu temps, especialment de les seues estimades "partides del Carme», on va nàixer i es va criar, com es pot comprovar en els tipus literaris i en els ambients populars que recrea, en va saber copsar amb gran encert el llenguatge popular característic. Un llenguatge que entronca amb la tradició lèxica, i lingüística en general, dels sainetistes del segle XIX, dels quals se sentia hereu, especialment d'Eduard Escalante. ${ }^{2}$

La seua visió enyoradissa i nostàlgica de la València antiga, que veu desaparéixer progressivament, sobretot en l'àmbit urbà, davant l'impuls de la modernitat i de les influències foranes, l'impulsa a recollir els tipus i els modes de vida tradicionals i populars abans que es perden definitivament, incloent-hi el seu parlar. Així ho posa de manifest en El carreró de la llanda (I9I7 [estrena I9I4], 2):

Desgrasiadament, poc a poc se quedem sinse la Valènsia castisa, la popular, la típica, la Valènsia dels nostres agüelos, la que portem cor en adins, ¡la Valènsia nostra! Les influènsies

I. El valor literari de la seua obra dramàtica ha estat assenyalat en estudis anteriors (veg. Sirera 1993).

2. En La pandilla (I936 [estrena I933], 9) posa en boca del poeta Manolo unes paraules de record i admiració a L'escaleta del dimoni d'Escalante. 
extrañes tot ho barrechen. Si volem vore sansers el viure, el sentir, el esperit, el sentiment del poble honrat, el que treballa y riu [...], ham d'anar buscant rincons y afores...

Juntament amb les altres tradicions valencianes, defensa l'ús de la llengua pròpia, del català, que, com diu "una valensiana fervorosa y arrogant», al final de Tra-ca-trac (1932, I5), cal conservar, com a element essencial que ens vincula amb els nostres avantpassats i ens aglutina com a poble. I per això, com el seu mestre Escalante, satiritza els «mals valencians» ${ }^{3}$ que, menyspreant la llengua vernacla, fan servir el castellà, unit generalment a un desig de progrés socioeconòmic mal entés, com trobem, entre altres, en El portalet de la chunga (1928 [estrena 1919]), „No és per ahí...! (1927) i Arròs en res (1930).

Hernández Casajuana, com a bon escriptor costumista, va saber retratar i satiritzar els canvis socials, que arribaven sobretot a l'àmbit urbà; igualment, com altres dramaturgs valencians de les primeres dècades del segle $\mathrm{xx}$, es va fer ressò dels canvis lingüístics, sobretot lèxics, que anaven apareixent en el llenguatge popular. De manera que en la seua obra, juntament amb formes tradicionals, es poden llegir veus i locucions absents en els autors del segle precedent. Entre aquestes veus ocupen un lloc important els mots col-loquials, ${ }^{4}$ però també els d'altres registres. Hi ha mots formats per derivació i composició, manlleus, de vegades amb canvis formals i semàntics respecte a la llengua d'origen, així com la creació de noves accepcions i sentits figurats.

\section{EL VOCABULARI}

Amb la voluntat de contribuir al coneixement de la història del lèxic català en una parcel.la poc estudiada, les línies que segueixen es dedicaran al vocabulari que, tant en la forma com en el sentit, documentem per primera vegada en el nostre autor, o en altres escriptors d'intenció popular del segle xx. La nostra idea ara no pot ser fer-ne un estudi exhaustiu, cosa que no permet l'espai disponible, sinó només reunir-lo, donar-lo a conéixer i comentar-ne els aspectes destacats, relacionant-lo amb els diccionaris i amb les obres contemporànies, centrant-nos especialment en els mots que representen alguna novetat respecte als diccionaris històrics i etimològics.

3. En el «miracle» Parlem valencià (I968, 8) posa en boca de sant Vicent Ferrer una defensa de l'ús de la llengua pròpia, unida a la identitat del poble valencià, i acaba: «Aquell que no parle / valencià enjamai / o tinga vergonya / del nostre parlar, / deveu dir-li sempre / que és mal valencià!».

4. Per a una visió de conjunt del caló en Hernández Casajuana, vegeu Sanmartín (1997). 
Joaquim Martí Mestre

El lèxic popular valencià en la literatura de les primeres dècades del segle XX:

l'aportació de Faust Hernández Casajuana

\section{I MOTS PRESENTS EN HERNÁNDEZ CASAJUANA I EN ALTRES AUTORS} CONTEMPORANIS

Blavet, aplicat, en general, als llauradors, als homes del camp, per part dels habitants de la ciutat de València: «Per la esquerra, un blavet, chaparro, gras, convenensiero y socarró» (Arròs..., 9), per referència a un llaurador de l'Horta de València; «Escolte, blabet, no me furgue» (Valènsia a la garson, 1928, 7), dit a un «ruquerol de la Plana». Altres exemples: «-Si ya no hi à chent de blusa! / Si tots van enchaquetats. / [...] Si ya d'aquells llauraorets / de la bluseta nugà / no se'n veu ni u! -Arrepare. / Blavets són la machor part, / sols qu·al córrer de la moda / la chaqueta se fan chas...» (Ferrer: Valènsia la chica, I928, 8), "que segurament m'ha pres a mi per un blavet, y de mi ningú se burla» (Alfonso: La casa de les gàbies, 1928, I3), d'acord amb la consideració d'ignorants i innocents dels pagesos, sobretot a la ciutat; «s'ha pegat en uns xavals / perquè li dien "blavet"» (Pensat i fet, 1929, I2), a Tonet, llaurador de Paiporta. Cf. paréixer dels blavets 'semblar ximple'. "Tu pareixes dels blabets. Pos que no saps que ya és hora de vindre, Juanito?» (Alfonso: Modistilles y estudiants, 1926, 9), i blau, probablement 'ximple, capsigrany', a Alacant: «Chic alt, gros [...], armà gresca en el café el dumenche pasat, y después que li romperen la cara, anava a dur una verga de bou, que, si no fa el gallina, haguera aprofitat pa ell. Che, no sigues tan blau, o si nós te tornarem encarnat a cullerotaes» (El Cullerot, 51, I897, 3).

Segons Martí Gadea (Tipos..., 25), el sobrenom de blavetss'aplicava "en la Ribera» als treballadors de la Marina que hi acudien «a la plantada y sega de l'arroç y demés faenes del camp»; igualment, a la Valldigna, els blavets són els bracers procedents de la Marina i l'horta de Gandia que hi anaven «con motivo de la plantada y siembra del arroz», mentre que a Gandia té un sentit similar al que veiem en Hernández Casajuana, però ara en relació amb la capital de la Safor, on anomenaven blavets, amb un cert valor despectiu, la gent de poble del sud de Gandia, en oposició als pixavins de la capital comarcal (Giner 2013: 95). ${ }^{5}$ Quant a l'origen de la denominació, per a Martí Gadea, el nom de blavets podria derivar «del moro Alazrach, conegut pel Blau, senyor que fon de les valls d'Alcalà de la Jovada y Ebo", o bé del "color més que moreno dels naturals de aquella comarca, els quals casi tots tenen el color prou pujat, al qu.ells mateixos li dihuen blau per conte de negre, en estil familiar y metafòrich». Coromines (DECat, I: 835) rebutja aquestes motivacions, i planteja la possibilitat de

5. Com a València, on els pixavins de la capital s'oposaven als durs, esclafaterrossos o blavets de l'horta. Sobre les analogies entre València i Gandia, coneguda popularment com València la Xica, veg. Martí Gadea (Tipos..., 366). 
JoAquim Martí Mestre

El lèxic popular valencià en la literatura de les primeres dècades del segle XX:

l'aportació de Faust Hernández Casajuana

relacionar-lo amb el cat. dial. blava 'mentida', tort. blau 'mentider', anàlegs al fr. dial. bleue, bleuse 'mentida', i les locucions deixar blau o quedar blau 'estupefacte' i ésser o fer-la blava (una cosa). D’altra banda, Zaragozà (I982: 199) afirma que el nom feia referència a la indumentària d'aquells treballadors agrícoles. Cf. blauet 'roba pagesa' ( $D A g$, I: 245), d'on facilment es podria aplicar als pagesos. La metonímia d'anomenar blau una persona vestida d'un vestit d'aquest color o caracteritzada per un accessori blau és prou habitual, i es dóna també en el francés bleu (veg. Rey 2006).

Bufanúvols 'persona presumptuosa, envanida' (...jM'he deixatles espardenyes!, I92I, I8; ¡No és per ahí..!, I927 [I926], I6; Valènsia la guapa, I929, 3), aplicat també a dones (La bella dona, 1963 [1936], 9), amb la var. bufanúgols (València a la garson, I7). En el $D C V B$ 'home presumptuós', doc. en Josep Pla. Coromines (DECat, II: 322) recorda que bufanúvols «s'usava un poc [...] cap a I9I5" i "que el va posar de moda Josep Pla». És també bastant utilitzat per Hernández Casajuana, i per altres dramaturgs valencians contemporanis (cf. Barchino: Valènsia... a trosos, I93I, I2), referit tant a subjectes masculins com femenins. El nostre autor el feia servir també amb el sentit de 'persona excessivament fantasiosa', no recollit en el DCVB, en el DECat ni en el DIEC: "Ponciano: - Ahí a hon el veus, cada paraula seua és una sentència. Ullà que ell pega, perdigonà que te clava; negoci que ell guipa, chavos segurs. Marcelina: -Mira, dina, que la debilitat t'ataca la cabesola, i tu en el perol buit eres bufanúvols» (;M'he deixat..., 7), «El tal Ferran, el metge, ha tornat al poble revolucionant-ho tot i en unes teories i uns trataments que Déu nos lliure; tot el terme va a servir-li de cementeri. [...] Ferran és un bufanúvols, un visionari...» (La masia de Masià, 1964, 19).

Mante, terme afectiu ('estimat, benvolgut'), per referència a infants: «Està dormidet... Fillet meu, mante, bonico!...» (La dona fa la casa, I925, 4), "Calla, filla, vine al meu cor. [...] Però no plores tu, mante meu» (València és teua, I962 [I93I], I4), a la filla; i a adults: "Pasa, mante, qu·estàs en ta casa. Arrepare quina llepolia» (L'airet de la matinà, I926 [I925], 9), dit per Chalele a Basilisa, "una criaeta de pur ñervi», "Marselina: —Sóc molt desgrasià! (Plorant). Benito: - No plores, mante; yo te compraré un pirulí» (La Marselina, I93I, IO), diu el marit a la seua dona, "Coalua: -Xica, Salut [...] Tens la casa a soles, mante...» (Gildo, I965 [I949], I2), entre dues dones; "L(e)udovico: -Elena, estàs hermosota...! Elena: —Vés-te’n, Ludovico, vés-te’n...! Ludovico: —Mante bonico! Elena: —No me digues mante!... Vés-te'n!» (Hernández, de Lara: Enredro de cachirulos, 1947, Bibl. Val., ms. 643-2I, 35). ${ }^{6}$ Reducció del castellanisme

6. Cf. «Niño de la Bola: - Sóc el Niño de la Bola, / y el millor flamenco és mangue. / És que yo tinc molta gràsia. / Nàsio: —Que no tens agüela, mante?» (Morante: ¡Nicàsia, Nicàsia!..., I93I, II), entre persones de sexe masculí. 
Joaquim Martí Mestre

El lèxic popular valencià en la literatura de les primeres dècades del segle XX:

l'aportació de Faust Hernández Casajuana

amante 'amant', que es doc. en textos populars valencians del s. XIX i principis del Xx, ex. "als qu.astilen / ser en totes molt amante, / y en ninguna» (Palanca: Secanistes de Bixquert, I867, 3I), «Sidra: - Si eres tan fi, tan amante, / tan repillo y tan blanquet... / Rafel: -No pases abant, Sidreta, / que.m dones mals pensaments» (Roig i Civera: En la nit de Sen Chuan, I884, Io), sovint en la referència als amantes de Teruel (o Tiruel), que degué influir significativament en la familiarització del terme castellà entre els valencians: "ya érem des de chicotets / amantes de Tiruel» (Palanca: Un casament en Picaña, I859, I9), "Enchamai tant se volgueren / els amantes de Tiruel» (Marçal: Els amants d'Alboraya, I862, BN, ms. I423I-IO, 23v); i com a vocatiu, en funció apel.lativa, prefigurant el valor de mante: «Pascuala: _Dóna’m les dos mans. Amante! / Que galtetes! Que cabell!» (Roig: El tesor dels chermanells, I884, I5), al seu estimat Purgatori; i que usava el nostre autor: "Vine, vine, fill meu, lusero, amante, bonico» (La sombra del Miguelete, I9I7 [I9I4], 9). A finals del s. XIX documentem mante, però encara amb el sentit d'enamorat, promés, amant': "Y què ha segut? / Alguna mala passà / que ha volgut fer-te el teu mante» (Palanca i Hueso: De la mort a la vida, I898, 32), en cursiva en l'original. El mot amante començaria a usar-se en val. per part de subjectes femenins, com un terme de moda, per referència als seus amants o enamorats, i després, per extensió, ja en funció apel-lativa, mante, desproveït del seu significat original, passà a emprar-se com a veu afectiva tant per referència a homes com a dones, i en aquest cas, com hem vist més amunt («mante meu» referit a la filla; "mante bonico», a la promesa), conservant en el seu complement la concordança masculina originària.

$M e c$. El nostre autor fa servir aquesta forma amb diversos sentits. I. Referit a un colp que hom pega a una altra persona, amb el verb pegar: "A mi poquetes espentes, / o d'un mec li avente el nas» (Valènsia a la garson, I6), «-Cállate, moniato. Vas a dirmos qu.és la teua dona la que té la culpa? - Home... — Te pegaba un mec!...» (La Marselina, 6). 2. 'Escarment, reprensió, recriminació, esbronc'. «Adelaida: —Tu eres home? Mentira! Un perdut! / Que el que deixa a una dona engañà, / ni té pit, ni té cor, ni ha sabut / lo que val una dona y honrà! (Pausa solemne. Paco, poc a poc, avergoñit, reconeguent-se, anà baixant els ulls y el cap, s'asenta y se tapa la cara en les mans). Furtatronchos: - Compañero, has sentit lo qu.han dit? / Ay, ma mare, quin mec t'han donat! / Víctor: -Deixem-lo y anem-se'n, que pa escarmentar-lo / vullguera ser algo de vosté, Adelaida» (L'airet..., I4), amb el verb donar. 3. Onomat. de la botzina d'un automòbil: "Mec, mec! (Bocina de auto)» (La sombra..., I2), cf. "A anar per lo carrer, mec, mec, fent roïdo...» (Martí Orberà: Chent del dia, I927, 40), amb l'automòbil.7

7. També onomatopeia de la corneta del femater (Llibret en la relasió y explicasió de tot lo que conté la falla de la plaza de Collado. Any I922, 8), i de l'acció de sonar-se els mocs: «-Meeec! / —Recristo! / Vés en cuidao al sonar-te» (Relasió y explicasió de tot lo que conté la falla de la plasa de l'Abre. Añ I925, 8). 
Joaquim Martí Mestre

El lèxic popular valencià en la literatura de les primeres dècades del segle XX: l'aportació de Faust Hernández Casajuana

4. Estar mec o deixar (algú) mec 'restar fet un beneitó', 'fer-li perdre el seny': "Si a mi no.m sap mal que.s riga. / Té riure de cascabell. / Per eixa risa tan fina / perc el compàs y estic mec» (La pandilla, 4), diu Victor a Pilareta, de qui està enamorat; "Benito: - Si vosté sabera... Cride a Pilareta. Hi ha que convénser-la; estem a temps. [...] Felipa: —Me deixa mec!... Però què té esta chica que se la rifen tots els galans?...» (íd., 24), en aquest cas referit a un subjecte femení; duplicat, tornar (algú) mec-mec 'fer-li perdre el seny': "La Sal: — [...] me pose a mirar / y al més terne yo.l torne mec-mec, / y una cosa me diu de pasà, / y la baba li cau sonrient» (Valènsia la guapa, 8); potser amb el sentit de 'prostrar, aclaparar', encara que també podria ser amb l'anterior: "Y así, Paulino Michavila. El campeó de moda. Boxea; va camí del peso pluma, perquè des de que va en Àsia que se està aprimant. [...] Vés, fica’t en Àsia; en dos chuts te fa gol y te deixa mec» (La dona fa..., 6). 5. Com a negació o rebuig, o per a desentendre's d'algú o d'alguna cosa, en la duplicació mec-mec: "Chordi: - Estos chics són una llibreria...! Matildo: - Muchos nos tienen anvecha al ver que nos ampinamos, poro a mosotros, mec-mec!» (La bella..., 8), «-Qu-aconseja al coven qu.entre en el estanco, que compre una garbeta arreu [...]. - Él tiene ganas de fumar y quiere ensender un sigarro de la garbeta, pero una vos oculta debajo del tablao le dise: ¡No te la fumes! ¡No te la fumes!, y él... mec-mec!» (íd., 9). ${ }^{9}$

En altres autors valencians del primer terç del s. xx es troba amb un cert valor onomatopeic de colp o d'acció contundent, sentit que cal relacionar amb els anteriors, especialment amb els dos primers: «-Ara vorem tu así qui eres. / —Pietat, socorro, que.m pega! / —Ya te tinc. / —Favor, perdó! / —No hi à perdó (Tiran-lo en terra). / -Mec! / -Pasteta! / Hasta el mànec (Supon que.l veu tremolant) / Com tremola! / Ya ha parat? (Pegan-li en el peu). / Che, no es menecha» (Bru Garcia: Els intrusos, s. a., I9), possiblement com una onomatopeia del colp; «-M'envenenaré en petròlio! —Y yo en pólvora! [...] —Chist! —Pum! —Mec! [...] Calabres els dos» (Barchino: L'aigua rocha, I932, II), expressió onomatopeica de l'acció de caure mort, "però mire, así a les onse de la nit, mec!, tot a fosques» (íd. Valènsia... a trosos, 6); onomatopeia

8. Trobem mec 'ximplet, beneitó' en altres autors populars valencians del primer terç del segle xx: «que vosté se creu que perquè vinc de la Riola estic mec?» (Barchino: La Java, 1925, 9), "(A Irene, cuant sona el timbre) Estàs mec» (Alfonso: Modistilles..., 4), "Però vosté està mec» (Buil: El milacre de l'art y de l'amor, 1926, I3); en el següent text l'autor juga amb la polisèmia del mot: 'ximplet, beneitó' i 'mena de colp': «—Vosté està mec! —Mec? El mec que te vach a pegar si n’has tocat algú» (Borràs: Guardes al camí, 1927, 24).

9. També es coneix en val. mec sense duplicar, com a expressió de negació, d'incredulitat i de frustració. Així, a l'Horta i a la Ribera "Això, mec!» «això no ho cregues», «això no és possible», i mec! per a dir que una cosa sembla poc creïble o s'ha frustrat, ex. «Volíem anar al cine. Mec, va ploure!»; a Elx, mec! per expressar incredulitat i negació (cf. Migjorn, 9-I3, agost de 2007, migjorn@googlegroups.com). 
d'un aparell electrònic que s'espatla: «Rom!, rum!, xit!, pum!, mec! Se m'ha estropejat el receptor i m'he quedat a lo millor» (Pensat i fet, 1932, 9), i la loc. dir mec 'dir quelcom': «que la seua germana Pepiqueta havia estat tota la vida pel Senyoret, que se l'estimava en silenci, i que hauria estat prou que ell diguera mec, perquè ella el seguira a la fi del món» (Olivares: L’estrep, 2005, 219). Al s. XIx, Bernat i Baldoví feia servir mec-mec com a onomatopeia del crit del sarcet (Martí 20II), i es documenta mec per referència a una beguda alcohòlica (Martí 2006), i amb el sentit de 'borratxo': "ya mitj mèc» (Pensat i fet, 1927, 7), "—Crec qu.estic un poc tocat. I - Tocat has dit? Estàs mec» (íd., 22, 1928, 9)..$^{10}$

Coromines (DECat, v: 548-550; DCECH, Iv: 47) creu que «en la major part dels significats és un mot de creació expressiva o onomatopeica», «quizà ayudado por el cultismo moechus 'adúlter', 'home femeller o efeminat'». Tant aquest filòleg com el $D C V B$ doc. mec per primera vegada en Eiximenis, amb el significat d'home sense pèl a la cara', d'on, per extensió, 'molt jove, home joveníssim si bé adult' doc. Procés de les olives, i el compost barbamec. El DCVB i el DECat (aquest a través d'Enric Valor) recullen el val. mec 'babau, idiota', ${ }^{11}$ i Coromines afirma haver-lo sentit a Barcelona "amb un sentit despectiu indefinible». ${ }^{12}$ Es relaciona amb formes anàlogues d'altres llengües, com l'occità mè( $(c)$, mèco, mèke 'celui qui est dans un état de stupeur, hébété, niais', ${ }^{13}$ el port. meco (doc. 1547 ) 'homem libertino, atrevido', 'home astut, maliciós', i el cast. meco, que, segons Coromines (DECat), «es troba en zones de vocabulari tirant al català o al gall.-port.» La forma meco no és desconeguda en cat., ja hem vist més amunt el barc. meco; també 'vedell desmamat' (Maestrat), 'animal que no té cua' (Mall.), 'noiet, xic' (eiv.), ${ }^{14}$ 'espantaocells, babarota', 'poll de cap', i a mall. funciona com a pron. indefinit negatiu $(D C V B) .{ }^{15}$

Io. El DCVB recull a Ciutadella mec 'borratxera', que relaciona amb el també men. memec 'constipat, especialment el de nas', el qual en el DECat es considera compost de mec.

II. Amb un sentit semblant també es coneix en tort. mec 'beneit, ximple' (Beltran 20IO: 544), i a la Llitera, mec 'prim, malaltís, queixós, ximple' (Giralt 2005: 318). \& Tasis I991).

I2. En l'argot barceloní mec 'estúpid, poca-solta', meco 'totxo, beneit', 'cop de puny' (Sánchez, Taixés

I3. També en fr. argòtic mec 'niais et poseur' (ap. Wagner i924: 7I).

I4. En el DECat (v: 549) es recull també a eiv. mecu 'muñeco, pelele' i, segons Fajarnés (2000: II8), ser un meco «es diu [a Eivissa] despectivament dels infants malcriats».

I5. Cf. bec, beco (amb [ع]) 'beneitot, curt d'enteniment' (en el DCVB beco, a Ripoll, Castelló i València) (i en $M G a d$ ), també bec (Martí 2006), i blèc, a 'encantat, embadalit, atordit, beneit, curt d'intel.ligència', a Benassal (Salvador 1943: 244). Segons Coromines (DECat, I: 744), beco 'hostal o restaurant dels barris vells de Barcelona' seria l'accepció principal, i 'beneitot, curt d'enteniment' facilment podria entendre's com una accepció secundària. Però si es tracta de derivar-la del barceloní beco 'hostal o restaurant' (doc. I839), no creiem aquesta explicació plausible per al val. beco 'beneitó. Beltran (2005: 164) considera el callosí bèco una variant de mec 'bovo, 
Miconina (El portalet de la chunga, I928 [1919], I3; La vista..., 3; Tra-ca-trac, I2; Gildo, Io), der. de mica, sovint, encara que no sempre, en boca de personatges valencians que proven de parlar en cast.; ${ }^{16}$ com miconino 'molt petit': "Doña Tonica, mire qué orejón; parese una cacaua de miconino» (;M’he deixat..., I9), cf. micona: "per a di-vos que no feu cas (ni micona) de les dones» (El Cullerot, 16, 1898, 3), i miconigua: «-Tinc vergoña. / —Tu, vergoña? Serà poca. / —Una miconigua» (Escalante i Feo: Les barraques, 1916, 315); mots no registrats en els diccionaris històrics i etimològics.

Panolla, i el masc. analògic panollo 'ximple, babau' (A la vora..., 3; El carreró..., 5; El solar de la pobrea, I926 [I916], I3; ¿Què pasa, che...?, I928 [I926], 6), cf. «-Vaya con los valensianos... ¡Pue lo que e a reí, a mi no me ganan! — (Este tio està panolla...; però panolla en pèl de bigot y tot» (Alfonso: ¡Encara viu!..., I925, 8), "Ell en ella està panollo, / puig en lo temps que rahonen, / li ha fet un or de meollo» (Ruiz: Formigueta d'or, I9Io, 35), també les loc. estar panollo (en un afer) 'desconéixer-lo per complet' (Llibret de la falla de la plasa de la Seu. Any 1925, 6), riurés com una panolla (Sendín: A la teua reixa..., I926, I2), i saber menys que una panolla (Pensat i fet, I932, 30). Accepció metafòrica de panolla no registrada en els diccionaris, formada per l'associació popular de les fruites i verdures amb la inèpcia i la manca de cervell (cf. bacora, bajoc, bajoca, carxofa, col, safanòria, que fan referència també a persones curtes d'enteniment, Martí 2006).

\subsection{ALGUNS MOTS O ACCEPCIONS ELS DOCUMENTEM NOMÉS EN EL NOSTRE AUTOR}

Acodonyat adj. «(Jaleo, roïdo i esclafits en el bar. Quan el roïdo ha arribat a lo més fort, apareixen com desafiats el Chulo fandanguero, Querànio i la Flamenca. El Chulo és el tipo presumit i fachendós de l'home valencià empeltat de fora. Querànio és "el xiquet de la bengaleta", chelàsio i acodonyat, i la Flamenca és una dona vistosa i apetitosa» ( $A$ la vora..., I5). No registrat en els diccionaris. Segurament derivat de codony 'badoc', que el $D C V B$ registra només a Menorca, sense doc. ('persona capclosa, curta d'enteniment'), però que coneixia també Hernández Casajuana, com a forma col.loquial val.: "Al que és tonto li diuen pàpil, panollo, boñ, codoñ, merengue i faba»

beneitot', que recull a Xàbia. De fet, fonèticament, l'equivalència acústica entre les labials $b$ i $m$ és possible, en totes dues direccions (cf. Veny 200I: I46-I49). Cf. també el verb becar 'badar, distreure's' i el substantiu becada 'error comés per distracció, badada'. No oblidem tampoc l'occità bèco 'enfant, gamin; niais, nigaud, pecque', que

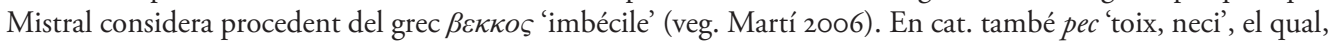
però, «decaigué ràpidament després de l'Edat Mitjana» (DECat, v: 355 ).

I6. Cf. «- ¿Pero ustedes pasan, o qué? -Aspérese una miconina, que a la chica se li ha desmorrellao la sapatilla» (Barchino: Valènsia..., 8). També es pot sentir parlant en català. 
(A la vora..., 3), «Tot hu trabuca; és molt codony» (El tenedor de Cullera, I928 [1926], I5), «-Che, bueno, però se pot saber a quin sant m'hau portat a este barracó de la placha [...]? -Eres muy corfudo, Benito. [...] Molt codony» (La Marselina, 5). ${ }^{17}$ Per a la motivació, veg. més amunt panolla; ací, a més a més, cf. l'estructura comparativa estar més verd que un codony, aplicat a una persona inepta o inexperta: «Està més vert que un codoñ. Que se'n vacha a la seua terra» (Tallada: El regal de boda, I925, II), per a torejar.

Atolondro 'atolondrament' (Gildo, 19) i desboco 'desmesura, exageració' (Traca-trac, 6) no registrats en els diccionaris; der. postverbals d'atolondrar i desbocar, respectivament, amb la terminació afectiva $-o$, que es troba en altres substantius en val. (cf. sossego, col.loco, escapo, espavilo, ${ }^{18}$ etc.).

Bufanda: «de chafanda, de bufanda» (La Marselina, 9), ${ }^{19}$ pipanda: «Colau, un compañero de pipanda» (La vista..., 25) i xafanda 'xala, menjar festós': «Mi Gasparo? De chafanda con los amigos» (;M'he deixat....', 19), ${ }^{20}$ provant de parlar en cast.; subst. der. respectivament de bufar, pipar 'beure begudes alcohòliques; embriagar-se' i xafar 'menjar' (A la vora..., 3; L'airet..., 4), de caràcter col-loquial, formats amb una mena de sufix -anda, indicador de l'acció de beure o de menjar. També papanda 'menjar, aliment', der. de papar, i manducanda íd.: «avent ajuntat-se els estudiants per a una folga o paseig, tocà a nòstron Pere portar la mogilla de la manducanda» (Planells: Resumen y relació de la vida y prodigs del religiós, el ven. pare fray Pere Esteve... Any I760, ed. facs., Dénia, 19), der. de manducar, d'on també manduca 'menjar, aliment' (Martí 2006). En cat. es coneix el sufix -and, -anda (procedent del gerundiu llatí), que forma adj. cultes o d'inspiració culta, com confirmand, doctorand, i alguna forma substantivada femenina com escuranda 'vaixella a escurar' (tort.) (López del Castillo 2002: 53; Rull 2004: 190). La terminació -ando, a en altres subst. cat. pot tenir uns orígens diversos:

17. Gayano el feia servir més aviat amb el sentit de ‘boig': «Que me muic yo? Vamos, calle. / Cuant yo dic qu.està codoñ!...» (;Bonica farsa!, I922, Io), «-U, u, u, u (Que tinc a la dona loca) / —Redell! / Que té la dona codoñ? (El mut afirma en el cap)» (Tofol Rosca, 1928, 8).

I8. «Ernesto, Pepe és com l'abre. / [...] Coloco dóna en la copa / a tots los ausells de l'aire, / pa que fasen niu en ella» (Alberola: Terres secanes, 1924, 33), «Esta compra és una ruïna. La chent té un espabilo ara!...» (Puig: Pantomima, 1928, I8) «—Què.t pasa? / —(No tinc escapo)» (Balader: Hostes vindran..., I885, I23).

19. Veg. bufanda 'borratxera': "hauran traques de colors, / [...] buñols, aiguardent y vi, / alguna que atra bufanda» (Llibret en la relasió y esplicasió de la falla de la plasa de San Bult. Añ I9I4, 6); cf. el der. bufandela 'beguda alcohòlica': «A l'atra, com no pose dos taules de menchuga y bufandela, no deu anar ningú a votar» (El Mole, 1864, 214).

20. Cf. «faran el dinar de gala / [...] Y després de la jafanda [...]» (Coles y coletes. Falla de Sen Josep dels carrers de Ciscar y Francesc Banquells en l'any I92I, I6), "Chafanda fallera» (Llibret de falla de la plasa Mosén Sorell. Añ 1922,7$)$. 
perfando, a, volando, pipiripando o piripando, marxando (DCVB; DECat, III: 889; VI: 554), i es troba també en la formació de renoms (Colomina I99I: 40). En cast. també es coneix el sufix d'acció -anda, -enda (Almela I999: II3), i la terminació -anda es troba en mots com parranda, usat sovint en la frase andar de parranda, val. anar de parranda; en el cas de bufanda pot haver-hi influït el joc formal de parònims amb el subst. bufanda 'peça de roba'.

Carquinyolar i carquinyolejar 'festejar, galantejar' (A la vora..., 4; Melchor, Gaspar y Baltasara, I927, 6; Arròs..., I3). Mot no registrat en els diccionaris. Entre festejants devia ser prou comú menjar carquinyols, que el nuvi regalaria a la xicona, com a signe d'afecte, com els cacaus torrats; cf. amb un sentit semblant la loc. torrar el cacau 'festejar', que fa servir el nostre autor (jM'he deixat..., I9), i altres escriptors populars contemporanis. ${ }^{21}$ També documentem, amb el mateix sentit, encara que més rarament, les loc. torrar l'armela i torrar la panolla, formades amb altres menges populars: «-Y que se volen de veres. / —Que si se volen? M'agüela! / Sempre estan torrant l'armela..., / y a mi.m fan unes denteres...» (Martín: La oroneta, I927, II), "La panolla estan pelant, / y atres ya la van torrant» (El tren fallero, I928, n. 5), uns enamorats, i les castanyes torrades: «Escomensen a estar en moda entre.ls nóvios les castañes torraes» (La Traca, I9I3, n. 105,2$)$.

Cascall 'vell, decrèpit': "No puc més, Coralina; me consumix este dissimular de vindre com a metge a fer partida totes les vesprades amb el teu marit i amb eixe cascall del metge vell, don Blai» (La bella..., I2), mot no registrat amb aquest sentit en els diccionaris. Segurament convé relacionar-lo amb cascarra íd.: "Y vosté,

2I. Cf. «Y si a pasechar la trau / y en les miraes deliren, / [...] no diuen tots els que.ls miren / qu.estan torrant el cacau?» (Peris Celda: Cacaus y tramusos, 1927, I), «-Y tu, què? A torrar el cacau en la finestra? -Què ham de fer? Rosario la Clavellinera me porta el cor de gaidó. - Sí que t'has triat bon foguer de chavala pa torrar-lo" (Barchino: La clavellinera del bàrrio, I93I, 5), i sobre la motivació de l'expressió, cf. "Als soldats y les criaes / els ham trobat mil vegaes / per la Glorieta confusos, / y elles van entusiasmaes / menchant cacaus y tramusos. / Cuántes conquistes s'han fet / obsequiant d'eixa manera! / Per el cacau torraet / h[a] hagut més d'una niñera / qu.ha asendit a ama de llet» (Peris Celda: Cacaus..., 2). El costum de menjar cacau estava molt estés. En un altre text, Ramon diu que els anglesos, quan van al teatre, «s'estan els nóvios menchant taronches aixina [a mos redó]», i Pere li contesta: "Com así menchem cacau...!» (Martí Orberà: Chent..., II). En la falla dels carrers de Mar i Congregació, amb el títol de «Les flors dels nostres jardins o Cacau calent», on es representen dos grups de festejadors, es llegia la inscripció: «Per gelat que sople el vent, / resulta qu.en la Glorieta / sempre està el cacau calent" (Pensat i fet, I9I8, 4), perquè s'hi solien reunir els enamorats. A més, en la imatge és present la idea de la calentor, en relació amb la passió amorosa. Així, el cacauero, veient les parelles que festegen en els jardins, crida «¡Ay, quins cacaus més calents! / ¡Cacau calentet, que crema!» (Falla de la replaseta qu.en lo carrer de la Mar té enfront la choriseria que hi à raere l'altar. Añ I9I8, 5). Cf. la loc. tindre el cacau torrat 'tenir núvia, estar compromés': "Pos tu no saps, marmolona, / que tinc el cacau torrat, / y qu·enchamay ha pensat / més qu·en la tehua persona?» (Fambuena: Un fransés en Almàsera, 1877, 7), diu Toni a Carmela, confirmant-li la seua estima, i el der. vida cacauenca, per ref. a les relacions galants, als festeigs (Falla de la replaseta..., 4). 
Joaquim Martí Mestre

El lèxic popular valencià en la literatura de les primeres dècades del segle XX:

l'aportació de Faust Hernández Casajuana

agüelo cascarra, / rey entre-ls hòmens mal fets!, / vacha y enseñe als chiquets / errearra botifarra» (Máñez: Bous sinse pa, I9ı8, 7), al mestre Pascual, amb menyspreu, "Ya sé, Llúsia, que volgueres / en conte d'este cascarra, / un flamenco, una guitarra / y un cuadro de peteneres» (íd., 7), li respon Pascual (veg. més exemples en Martí 2006), i cascarrat 'decrèpit, xacrós': «—Hoy! Agüelo cascarrat. / —Més val això que gandul» (Barreda: Parents de la dona, s. a., BMV, ms. MG 367 (2), 64), «Rita: -Filla meua!... Com estem? Concheta: —De primera..., y vostés? [...] Cheroni: -Algo cascarrats..., però estem bé» (Beltran: El millor castic, I925, II), Cheroni i Rita són dues persones ancianes, que tenen les febleses físiques pròpies de l'edat.

Encabironat, -ada: «Timotea: —Qui està per ací? Paxorra: —(La Timotea! Lo tendral i lo encabironà que està! Una cafisà m'agrà a mi la vedelleta esta, dende que ha tornat al poble de servir en Madrit...» (La bella..., 8), aplicat a una dona ben plantada, però altiva i difícil d'aconseguir; "Rosa: - Paco Tarima està colat per tu [...] Li dius que baixe la Lluna, i de seguida agafa el tramvia dels núvols, i a la Lluna. No te diré que la baixe, perquè està molt encabironà, però una estrela, te la porta pa ferte un dije» (íd., 6I), és a dir, molt alta, molt difícil d'assolir. Accepcions metafòriques, per l'altura dels cabirons; no enregistrades en els diccionaris.

Engraellar-se (un assumpte) 'embrollar-se, complicar-se': «-És que yo estic fent-li l'aleta a esta viuda. [...] — No, pos mira, faràs més choc en ella que su difunto Llopis. [...] — Pos a l'aparéixer este piloto, s'ha engraellat el asunt» (¡No és..., II), estar engraellat (per algú) 'estar-ne enamorat': "Doña Regalísia és una jamona encara prou fresca. [...] Se mira en sa filla Claudieta, y a vegaes se creu qu.és ella. No té més obstinasió que agradar al sr. Rufino, qu.està engraellat per la chiqueta y a sa capa el saquechen a mansalva» (El solar..., II); com a substantiu, engraellat I. 'Assumpte embrollat, incomprensible': "Mangue està así y la siñora defensora està en la chipé, perquè yo estic en el tríngulis del cónquibus de tot este engraellat» (La vista..., 2I). ${ }^{22}$ 2. 'Llengua incomprensible': «Este que va en la nau nostra / és Gatuf, brau mariner / que nos parla un engraellat / que nosatros no entenem» (Parlem..., I3), i, humorísticament, per referència a la llengua d'un quec: «—El meu Cheroniet, ya sé qu·és un poquet duret y el parlar el té un poquet barallat. —Un poquet barallat? Calle, dona, si és un engraellat: trac-traca-trac-pum!» (El tenedor..., I5); accepcions metafòriques, col.loquials, no registrades en els diccionaris. ${ }^{23}$

22. Cf. «Però si yo estic dechú / de tot este engraellat» (Martín: ¡Baix la figuera!, 6).

23. Cf. engraellat 'conjunt de masclets o morterets arrenglerats en dues fileres tupides': "y La Traca està ya preparant els masclets, y l'engraellat y les canterelletes, y tots los dimonis de l'infern, per a tirar-li-los entre cames a tot aquell que, tiran-la de conservaor, no vullga conservar atra cosa que.ls enredros y els embolics y les coses brutes com els empastres dels Hospital[s]» (La Traca, I884, n. 6, 4), i 'soroll alt i confús, rebombori': 
Joaquim Martí Mestre

El lèxic popular valencià en la literatura de les primeres dècades del segle XX: l'aportació de Faust Hernández Casajuana

Escampabufa: «- ¿Y su marido? — ¿Quién, mi Gasparo?... De chafanda con los amigos. En haser un dia festívolo, ya se sabe, escampabufa general" (;M'he deixat..., 19), parlant en un cast. ple de valencianismes; amb un sentit diferent al del $D C V B,{ }^{24}$ per relació a l'acció d'anar-se'n de xala, aprofitant la festa i el bon oratge, i el verb escampabufar-se 'anar-se'n, absentar-se d'un lloc', no registrat en els diccionaris: "-Yo crec que, abans de que mos penchen càguila, debem anar-se'n... - Antes que se escampabufen, la denunsia por conglomerasión en la via pública» (Arròs..., 4).

Malbé 'tort, malcuinat': "Casildeta: -El pare Vicent Ferrer / no cap dubte que és un sant... / Dimas: —iI això per què i a què ve? / Casildeta: —El cor dient-m'ho està. / Dimas: —És frare que es meneja, / predica sense parar, / en tot malbé me'l mesclen, / se fica en tots els cuinats / i al remat, rebolica, / solta uns sermons i se'n va" (Sigau bona gent, 1959, 17), amb un ús com a substantiu, que no figura en els diccionaris. En el $D C V B$ només fer malbé 'espatllar; deteriorar fins a deixar inservible o gairebé destruït'. En el DECat (v: 382) es diu que fer mal bé té el significat originari de 'fer mal profit, anar a perdre's, fer mala fi', amb ascendents medievals, d'on fer-se malbé 'malbaratar-se', i que és «usat per tota mena d'escriptors del Principat i de les Illes des de l'Atlàntida». Però fer malbé (quelcom) 'malmetre-ho' no és desconegut entre els escriptors valencians del s. xIx i primer terç del xx: «Yo no deixe fulla verda / allí a hon trobe la ocasió. / Fas malbé més fruits que menche, / estiguen o no en sahó» (Un pillo y els chics educats en la casa de Benefisènsia..., I846, 23), diu el pillo, que furta i malmet les fruites dels llauradors; «eixe [dimoni] [...] és el representant del que tot vol mangonechar-ho y dirichir-ho, y que tot mos heu empastra y mos heu fa malbé (Llibret en la explicasió y relasió de la falla del carrer de Alboraya, I9I4, I), "-Les fâbriques de plats no ne fabriquen prou per a qu.ella els trenque. - Señal que.ls palpa molt, que.l que no toca una cosa no la fa malbé» (Fink: La millonària, I918, I2), i també en el nostre autor: «a on falta un home / allò que és bo es fa malbé» (Parlem..., I2), "Sempre que ell ve a l'hort, falta una gallina o se fa malbé una planta» (València és teua, 3I), i aplicat a persones: «-I no agafaren als lladres? / —Vingué un lladre fet malbé / la mateixa nit del robo / a este hostal buscant remei, / puix se ferí en una cama / i córrer no pogué més» (Sigau..., II), és a dir, ferit, malmés, i en fer malbé (un

«y a vegades tal orquesta / resulta un engrahellat» (Las Provincias. Almaque para 1908, I29), «El poble s'ha estat dos dies, / Dijous y Divendres Sant, / dejunant, sense dir pruna, / [...] y renega del silenci, / alsant un engraellat / de xiulits, veus y disparos» (íd. 1909, 262), quan arriba Pasqua.

24. En el $D C V B$ 'escampadissa de coses, especialment en certs jocs en què s'escampen cartes o diners', com a val., sense doc., cf. per relació a una escampadissa de panquemaos: "(s'encula un poquet la post, y roden uns cuants panquemaos per terra) [...] Chelàsio: —Escampabufa de panquemaos! (Arreplegant-los)» (Barchino: ¡Tot a perra!, 1931, IO). 
Joaquim Martí Mestre

El lèxic popular valencià en la literatura de les primeres dècades del segle XX:

l'aportació de Faust Hernández Casajuana

menjar) (a algú) 'fer-li mal profit, ocasionar-li problemes de salut': "Este matí... l'han porgat [el cavall], perquè anit li donàrem safanòries i li han fet malbé» (Gildo, 3I), que recorda el sentit que té en Muntaner (DECat, v: 382$).{ }^{25}$

Manyequera: "L'eixauar comercial és curt: una cadira baixeta, un canut amb dos agulles saqueres, [...], una boticha nana, manyequera, però que, segons diuen, fa un.aigua freda que engisa» (; $M$ 'he deixat..., 5), mot no registrat en els diccionaris. Possiblement, der. de manyaco o manyeco, que, juntament amb les var. monyaco, monyeco, monyanco, monyicot, munyicot, i altres, s'apliquen als infants (cf. Martí 2006). Les característiques de la boticha («nana») podrien donar suport a aquesta interpretació.

Pessetol: «Drapero: -Arrepare lo que li porte. (Bufanda para la mà y chavo a chavo resibix el import; a cada moneda, una cara d'alegre sonrisa). U, dos, tres, cuatre, sinc y pesetol. Sis quinsets, de tres pesetes; la mitat pa vosté, y l'atra mitat pa mi» (;Eh, la beta!, I5), fa referència a la pesseta i mitja que dóna el draper a Bufanda, de la venda del catret, "Jo tinc que tornar-li un pessetol que va sobrar de lo que vosté me donà pa estanyar els cànters de la llet» (València és teua, 56). Mot no registrat en els diccionaris. En el DCVB pessetó 'moneda de dues pessetes' (Pont de Suert, Fraga), sense doc. Cf. pessetola, sinònim de pesseta (MGad, com a veu familiar), ex. "Has vist? Una pesetola» (Escalante i Feo: Mariquita la estanquera, I889, I8), "Asò és una mina! Este pato és un talismà! Pesetola ha caigut! Està pagant el pato, peseta a peseta» (Pagar el pato, I926 [I925], 5).

Pipiula!: «—Doloretes, la neboda de Tarañina el pilotero, està... està..., està...! —Què me dius! Y és el sargento de Atministrasió per fi, se sap sert? —-Tots diuen que.l de l'Atministrasió és el que la atministra, però pa mi, pipiula! Tot Chamarrusquia! —Com?» (La oroneta..., I3), fórmula usada per negar, rebutjar o desmentir una afirmació. Amb un sentit semblant, al s. XIX doc. pipiu!: "Al saber-o, / la viuda em trenca la cara, / mos tira als dos, y el beato, / al saber la saragata, / fa heretar a mon cosí, / y a mi, pipiu!» (Palanca: Lord Guillaume, BMV, ms. MG I58, I2), és a dir, el deixa sense herència, "y me da lástima / de verla cómo lo popa, / lo contempla y agasaca / para engarbarlo en su chico [per chica], / y, pipiu!, de baldes malla, / porqu.él mira su anterés, / y es otra la que lo engarba» (Balader: Hostes vindran, I885, II3), en un castellà ple de catalanismes; que cal relacionar amb l'expressió de burla pipiu mamau: "Manuel: —Vés-te’n, deshonrat! / Isidro: —Y el perol? / Benito: —Com! / Isidro: —El perol que teníeu amagat. / Benito: —Mare mehua! / Mònica: —Som perduts! Isidro: —Mireu-lo, pipiu mamau! (Fent-los la mamola y enseñant-los el perol huit) / Benito: -Y els dinés? I Mònica: —Y el meu tesor? / Manuel: —Ya està en puesto, y no es pedrà» (Palanca:

25. En EscLl i MGad fer malbé sinònim de malbaratar. Joaquim Urios recollia a Borriana fer malbé: ho has fet malbé 'lo has estropeado, lo has hechado a perder', i s'ha fet malbé (Buris-Ana, I5, 1957, 3). 
Joaquim Martí Mestre

El lèxic popular valencià en la literatura de les primeres dècades del segle XX:

l'aportació de Faust Hernández Casajuana

Ortigues y roselles, I874, 25), el perol contenia els diners que Benito i Mònica cisaven al seu oncle Manuel, el vicari; i quedar-se (algú) pipiu mamau 'restar burlat' (Martí 2006).

Potim: «—Yo la vacune a vosté contra la pigota [...] —-Mire (Traguent d'un bolso que porta), así està el canonet del potim, esta la llanseta, así el cotó·n pèl y la botella de l'esperit pa llavar-me-u» (Capitulé Tonico, I9I8 [I9I7], IO), pel medicament, la vacuna, que li administra; i empotinament (text ampotinamientos, castellanitzat): «Mira, Mília, no espigoles, que aluego tienes ampotinamientos en el estómago. ¡Es más llépola!» (:M'he deixat..., I9), en boca d'una antiga venedora de tanda del mercat, que parla un castellà ple de catalanismes, la qual adverteix la seua filla que si mescla tants fruits secs, se li embrutarà l'estómac. En val. es coneix potim 'espècie de quitrà molt tou, i que per tant ja no cal escalfar, per aplicar-lo a les barques de l'Albufera' (El Palmar, I962), 'pintura molt basta emprada per a pintar els plans de les gavarres' (DCVB; DECat, vi: 764), conegut també com a sinònim d'asfalt; juntament amb empotimar 'asfaltar (els carrers)' (Sollana) (<http://sapsquevulldirte.blogspot.com.es/2009/Io/>), i el postverbal empotima 'empastre': "la paella valenciana no lleva ni ajo ni pimiento ni costillas de cerdo; eso en mi tierra es una empotima» (<http://www.youtube.com/ watch?v=4k8PiNuuJbE $>$ ); a Olot empotinar 'embrutar' (DCVB). Segons el DECat(vi: 762-765), mots derivats de potina «nom dialectal d'una barreja fastigosa de menjars o begudes», d'un llatí *PULTINA, der. de PǓLS, PǓLTIS 'farinetes, farro'.

Puf: «-Quina estoreta més llargueruda!... —-La del pati del marqués, gica; del marqués és també la levita que porta eixe ninot de les patilles. Quin puf de casa! Tot se ho ha menjat la justícia...» (Pensat i fet, I9I3, I5), dos vellets, comentant els objectes de la falla, procedents dels veïns del barri, per referència a la desfeta de la casa del marqués. També en la loc. pegar un puf: «(Se ou un roïdo com de redolar. D. Fulgènsio ha esvarat y cau a trompaes per la escaleta) [...] —Què, no s'ha mort? —No ha segut res; moltes gràsies. / [...] —El pobre periquito sí qu.ha pegat un pufi (El carreró..., II), el periquito que duia $D$. Fulgènsio en una gàbia. Mot de caràcter expressiu; cf. la interj. puf(Riera-Eures \& Sanjaume 2002, I84).

2.3 Tot i que ara no els podem estudiar amb més detall, citem altres mots o accepcions usats per Hernández Casajuana que documentem a partir del segle xx (alguns només en aquest autor), alguns dels quals no inclosos en els diccionaris: abadejo (tipus d'estel tradicional) (:M'he deixat...!, 13), acabacases 'balafiador' (L'airet..., 3), cf. arag. acabacasas 'dilapidador, manirroto' (Andolz 2004; Endize); albuferenc 'barqueta per a navegar per l'Albufera' (Òpera flamenca, I963 [I930], 57), i llanxeta albuferenca (Gildo, 3I); alçar (una casa) 'tancar-la, deixar-la, per mudar-se de casa') (La masia..., 88), alcavor 
Joaquim Martí Mestre

El lèxic popular valencià en la literatura de les primeres dècades del segle XX:

l'aportació de Faust Hernández Casajuana

'cordialitat, afecte, amor' (La dona fa..., II), ampudegós, a (Lo millor del món, la dona, I93I, 5), apantalonar 'donar la forma de pantalons', i entrecamar (faldeta entrecamà, és a dir, situada entre les cames, imitant la forma d'uns pantalons) (La Marselina, I3); assaonada (una dona «garbosa» $\mathrm{i}$ «escultural») (Òpera..., 57), assorrar-se (el reuma) 'assentar-se, afermar-se, un mal en una part del cos' ( Eh, la beta!, 7), barraqueta, botigueta i cachol [sic] 'mentida' (A la vora..., 3), barrenaire (ulls) (La dona per dins, 9), cf. barrinaire doc. I839 (DECat, I: 689); bonestar 'benestar' (El portalet..., I9), bony 'ximple, babau' (A la vora..., 3), ${ }^{26}$ boquillós (La dona per dins, 5), mot insultant; botataulells 'botiguer', en sentit despectiu (;No és per ahi...!, 9), bufaplats (;M'he deixat..., 6), terme insultant, entre unes dones; cacau 'gresca, confusió' (El tenedor..., I3; Arròs..., 3) i cacauar 'lloc on regna el desordre, la confusió' (El pati..., 26; L'airet..., I5), caliu 'calorós' (adj.) (Quina animeta!, I27), calàndria 'mentida, falòrnia' (¿Què pasa...?, 8-9), canyot, fig. 'persona molt gran, molt alta' (El carreró..., 5), caparrós 'capsigrany, capbuit' (La masia..., 49), cf. caparró 'persona eixelebrada, de conducta lleugera' (DIEC); carreronera (dona) (El pati..., 22; ¡M'he deixat..., 6), cf. gent de carreró (Martí 2006); claret 'sobri' (La vista..., 24), clec 'espècie de botó' (El portalet..., I7; La masia..., I4), corfut 'badoc' (L'airet..., 5; Parlem valencià, I968, I4), cf. corfa i corfoll (Martí 2006); corruco 'pasta dolça' (¿Què pasa,...?, 7, 9), fig. com a galanteria a una dona (El pati..., I8; El solar..., I3), i en la loc. fer-se el corruco 'fer-se el desentés' (;Eh, la beta!, 3); coure (un constipat) 'guarir-lo' (;Eh, la beta!, I9I7 [I9I6], 5), en el DCVB es recull només al Camp de Tarragona, a Mallorca i a Menorca, sense doc.; cuiro 'badoc, ximplet' ('Quina animeta!', I33), culforadat ("puals culforadats») (Elcarreró..., 3), desficaciar'dir desficacis' (Deprop, 1916, 573), despellogar-se 'desfer-se (d'algú o d'alguna cosa)' (La pandilla, 1936, 23), despollastrat «eixe tio despollastrat» (El carreró..., I7), per Don Fulgènsio, "un agüelo vert», cf. l’agüelo Pollastre de Bernat i Baldoví, un altre vell verd, paròdia dels valors de joventut, arrogància, valor i seducció del Tenorio (cf. Martí 2009: 338); dormicar 'dormitar' (La dona per dins, I2), eixaropós: "una veu tan dolsa y eixaroposa» (Explicasió y relasió de tot lo que conté la falla dels carrers de Maldonado, Ànchels y Monches Servites, I918, 7), emboquillat'afectat, petulant' (La dona fa la casa, 5), entortilló: «El foro se pert entre entortillons de fachaes traseres que s'entren y sinse vore el final del carreró» (El carreró de la llanda, I9I7, 4), ${ }^{27}$ relacionat amb el verb entortillar (El pati dels cañarets, I9I4, 7; La dona per dins, I930,

26. Cf. «Marieta: - Vols dir-me qui és ella? / [...] Tofolet: —Te hu dic? / Marieta: —Digues. / Tofolet: —Una que yo sé. / Marieta: —Che, parla y no sigues boñ» (Vidal: El bastardo, I922, Io), i estar (algú) bony 'estar estupefacte, esbalaït, aturat': "Abel: —Marieta! / Chimo: —Ma filla! / [...] Ernesto: —Sa filla, sí, la mateixa. / Ella és l'ànchel beneït / que.l meu cariño sustenta. / [...] Chimo: —Yo estic boñ!» (íd., 6).

27. Cf. entortilló amb sentits una mica diferents, 'torçada de peu': «Vaig pegar un entortilló al baixar l'escala i es veu que se me’n va eixir un tendó del lloc» (Forcada: Les Camiles, 1974, I65), 'caragolament de ventre, retorçó' (Segura 2003: 272). 
22; La vista causa de Mary Hetta, I93I, 24); escorredor 'corredor, passadís' (íd., I3, I4), filadeta 'desfila' (Capitulé..., I2), fortària 'força, fortalesa' (La oroneta..., 24), lligasser 'que lliga' (La bella..., I2), martingalero (:Quina animeta!, I9I4, I32), der. de martingala, cf. martingaliste: "Però si és esta, que sempre està dient que si el Gallet obri les tisores, que si és un martingaliste...» (Peris Celda: La afisió, I9I7, IO), discutint sobre toreros; mescla 'companatge' (Parlem..., I2), ${ }^{28}$ mesclam (Valènsia a la garson, I9), der. col.lectiu de mescla; ormeig 'xala' (La vista..., 4), palometa 'candela que sura en oli' (La oroneta..., 8), perilla 'bombeta' (Melchor..., 3), pàvil (Elsolar..., II), pavil (La pandilla..., 20), pàpil (A la vora..., 3) 'ximple, babau'; porrito 'titella' (Explicasió..., II; El portalet..., I6; ¿Què pasa...?, 7), pudent 'tràgic, penós, dramàtic' ( Eh, la beta!, 8), pudentina 'pudor forta' (El carreró..., 7), quall 'paciència' (La bella..., I7), tella 'pesseta' ( $E$ h, la beta!, Io), terraplenada (Lo millor..., 20), aplicat a una dona ben plantada; tombabastos (La masia..., 69), compost de bast 'albarda curta de les bèsties de càrrega'; xarpa 'sorda' (Gildo, 58), xurra 'criada, serventa' ( $E$ Eh, la beta!, II), natural de Carcaixent; per extensió, ja que moltes de les serventes que treballaven a València eren de procedència aragonesa o de les comarques valencianes de parla castellanoaragonesa ("xurres»), d'ací que el terme xurra s'apliqués a les criades en general.

\subsection{NEOLOGISMES LLIGATS A LA MODA, O ALS NOUS COSTUMS SOCIALS}

La majoria són manlleus, encara que també n’hi ha de formació culta, comuns amb altres llengües modernes. Juntament amb formes que continuen en la llengua literària actual, s'observen casos de vacil.lacions en l'adaptació d'alguns manlleus o cultismes, les quals de tant en tant es mantenen en l'actualitat. També fa servir algunes formes, de vegades derivades, que no semblen tenir continuïtat en la llengua actual. Notem, així mateix, la presència de formes i variants no recollides en els diccionaris. Bidet (La flor del voler, 1930 [I927], 8), bistec (L'airet..., 7), boc (de cervesa) (L'airet..., 4; ¿Què pasa...?, II); bullavés (L’airet..., 7) (fr. bouillabaisse), carei, carrei: "ulleres de carey» (La Marselina, I3), "de carrey» (Valènsia a la garson, Io); cinema (Tra-ca-trac, 6) i cine (Arròs..., II; Tra-ca-trac, 6), i els der. cinematografar (algú) 'escrutar-lo' (La vista..., 20), i cinematografat, -ada 'influït pel cinema', pejorativament, aplicat a una dona moderna (;M'he deixat...!, I7-I8); ${ }^{29}$ crupier (L'airet..., 5), couplet (La bella..., 4; ;M'he

28. Cf. «ells correguent al treball, / y en un saquet, a hon s'emporten / la mescla de l'almorsar» (Llibret de la falla de la Vallà de San Fransés, I903, 7).

29. El cinema era un invent recent associat a la modernitat i als canvis de costums, i per això el pensament tradicionalista el veia amb prevenció, més encara per relació a les dones, que per aquells anys començaven a 
deixat...!, 23), cuplet (Tra-ca-trac, II), ${ }^{30}$ i cupletista (;M'he deixat...!, 23); ${ }^{31}$ feminisme (La dona fa..., 3), feminista (íd., 4), fototipia (Capitulé..., 9), foagràs (Falla del carrer de la Pas eixecutà per el Sírcul de Belles Arts. I924, I), foxtrot (jM'he deixat...!, 25; Valènsia a la garson, I2; Valènsia la guapa, 9) i la var. escurçada fox (La vista..., 20), amb s, fostrot (Arròs..., 8), i castellanitzada fostrote (;No és..., Io); ${ }^{32}$ frégoli (:M’he deixat...!, I5), tipus de barret; gànster (La masia..., 83), glaxo (pl. "glaxos») (La Marselina, I3), ${ }^{33}$ i clàxon (L'airet..., 7), cf. la var. claxons, amb accent gràfic sobre la $o$ : «T'ataranten els timbres, bosines, bosinaes, chafaes, espentes, claxóns, autos, avións, patinéts, rayos, sentelles» (Explicasió y relasió de tot lo que conté la falla plantà en el carrer del Pintor Sorolla, a on estaba la font dels Patos. Any I93I, 7); hipe ("gorreta hipe») (El carreró..., 4; L'airet..., 5), cf. «Barilla [...] vist trache de pana vell, descolorit y runós, y gorreta ipe» (Soler Peris: La casa misteriosa, I9I7, 7), era també el nom d'un joc de nois: «(jugar) a gorreta hipe» (Llibret de la falla del carrer de Lluis Morote (antes Cherusalén). Añ I923, 6), que l'autor d'un llibret faller, humorísticament, veia com el precedent valencià del futbol (Plasa de San Bult. Añ I923, 5); jazz-band i jas-band 'banda de jazz' (Valènsia a la garson, I8, I9), pl. jas-bans i jas-bansos (íd., I7, I8), i el der. jasbaneo (íd., I8), ${ }^{34}$ mallot

trencar amb el paper subordinat que tradicionalment hom els havia assignat. En un altre text contemporani, Micalet usa el der. cinera per insultar Benita: «Micalet: —Falsa! Benita: —Mal home! Micalet: —Sinera! Benita: —Idiota!» (Marco Rivas \& Mínguez Llorca: ¡Un loco cuants ne fa!, 1928, 6).

30. La forma més estesa en els textos val. de l'època és cuplet, però també s'hi troba la no adaptada couplet (Bernat: Casiquisme roig, 1904, 67; Soler: ;Mos quedem!', 1907, 56); més rar, cuplé (Barchino: La Caraba, 1926, I4), coincident amb el cast., d'on deu procedir; també amb o, coplet: "Coplets de la Molinera» (Peris Celda: Valènsia de dia, 1918, 9), "Cante el coplet del Sariero» (Ferrer: Valènsia..., 9), i els der. copletista, copletistra i copletera: "Com no ne vullgues uns [pantalons] de copletera..." (Peris Celda: El debut de "Col y Flor», 1917, I2), «la meua dona es vol fer copletista» (Navarro: La mala senda, 1926, I3), «Com anàbem a creure que vosté estiguera borracho, chillant dalt de un automòvil, en compañia de unes copletistres?» (íd., 5), explicables per les vacil-lacions que es donen en val. entre $o$ i $u$ àtones, i la tendència popular a canviar $u$ en $o$.

3I. Juntament amb cupletista (coupletista, copletista), doc. cupletera (coupletera, copletera), i els masculins cupletero 'autor de cuplets' i cupletisto 'intèrpret de cuplets', ex. «Una hermosa cupletista / (atres dihuen cupletera)» (Relasió y explicasió de tot lo que conté la falla situada en lo carrer de Fresquet, 1916, 4), «Escola de cupleteres» (Haro: Escola de cupleteres, I92I, I), "Che, cupletero! Què estàs parlant?" (Costa: Hòmens i dones de carn, I934, 8), i com a adj., «eixa plaga cupletera» (Gran falla... dels carrers Alt y de Sent Tomàs, I9I8, IO); «El dia menos pensat el voràs debutar de cupletisto» (Peris Celda: El debut..., 9), «Ix Don Juan, un mestre de cupletistos aprofitat y algo raro» (Peris Celda: Una achuda, 1925, I5).

32. Cf. la var. foxtró (Llibret en la explicasió y relasió de tot lo que conté la falla dels carrers de la Encarnasió y Pintor Domingo. Añ I922, 5) i els verbs der. foxtrotar (Falla del carrer de la Pas..., I) i foxtrotejar, en la loc. foxtrotejar la llengua 'provocar errors de dicció': «—Per què no fa una pasaeta de película? - No estic ara en "poss» —Vosté tindrà admiraors $[\ldots]$ que se mosegaran per vore-la fent «pis». - Fent «poss». —Com se diga, perquè a mi tot lo estrancher me foxtrotecha la llengua» (Sendín: Tonica la del llunar, 1926, 6).

33. Cf. «(S’ou el ruïdo del glaxo de l'automòvil)» (Barchino: La forastera, I93I, I6).

34. També aplicat a la música de jazz, que hom ballava: «si anem un poc a presa, / ballarem l'últim jaz-ban» (Llibret de la falla dels carrers de Pascual i Genis i Mosén Femades. Any 1922, 9), "va a ballar / [...] chotis, 
(Arròs..., II), massatjar (una persona) (Tra-ca-trac, I2), sembla derivat de massatge; mitin (La dona fa..., 7), ${ }^{35}$ papillot ("guisao a la papillot») (Melchor..., 8), paraigües tom-pus (La Marselina, I3), pendantif (Pagar..., 3), petroliera (La sombra..., I2), plexiglàs (La masia..., 53), i la var. peixiglàs (íd., 83), quiosc (pl. kioscs) (A la vora..., I7), rimel (La bella..., Io), rosbif (L'airet..., 7), spiker (La dona fa..., 5), taxis (Tra-ca-trac, 6), en singular; ${ }^{36}$ toalet (La bella..., 9), trinxera (tipus de gavardina) (Valènsia a la garson, Io), troupe (íd., I8), wàter (La flor..., 8) i wàter-closet (Falla del carrer de la Pas..., I), ${ }^{37}$ xòfer (;Eh, la beta!, 9), la var. xufer [chufér en el text] (íd., I3), jugant humorísticament amb el parònim xufer (der. de xufa), el pl. xoferos (text choferos) (Valènsia la guapa, 7), i la forma no adaptada chauffeur (La bella..., 575). ${ }^{38}$

A principis del segle xx es posaren de moda els neologismes, generalment anglicismes, lligats a l'esport. Destaquen en aquest sentit els relacionats amb la boxa i, sobretot, amb el futbol, que, des d'un primer moment, assolí un gran èxit popular. Així, en la boxa, conaud (La dona fa..., 6) (angl. knockout), faud (íd., 6), grogui (Enredro..., 62), ring (íd., 65) i run (La dona fa..., 6) (angl. round). Quant al futbol, com a nom de l'esport, Hernández Casajuana fa servir la forma futbol (Tra-ca-trac, 7, I5), aguda,

foxtrots i jazzbans» (Explicasió y relasió d'una falla colosal anomenada "València», s. a. [1923], 2); cf. les loc. fet el cor un jazban 'estar molt content i alegre' (Pensat i fet, 1927, 7), ser (un lloc) jazban 'haver-hi molt de rebombori, molt de soroll' (íd. I93I, 3I) i tocar més que un tio del jasban (Tallada: El regal de boda, 1925, 4), que proven la popularitat entre nosaltres d'aquest nou tipus de música durant els anys 20 i 30 del segle passat.

35. Cf. miting: «reunions, vetlaes i mítings» (Bernat: Casiquisme..., II9), i el pl. métines: «Veu les huelgues y amenases, / métines, crits y carases» (Peris Celda: Valènsia de dia, 1918, 9).

36. Aquesta forma es troba sovint en els textos val. populars de l'època. Ex. "en cónter de taxis» (Barchino, Vidal: A la lluna de Valènsia, 1925, 9), "Que acaba de parar un taxis d'eixos en la replaseta del cantó» (Peris Celda: President de honor, 1927, 39), «alquilaré un taxis» (Casinos: L'avespeta, 1927, 13), «Fes el favor de anar a per un taxis, Baldomero" (Casinos: Deixa’m la dona, Pepet, I93I, 52), "veches si per ahí hi à un taxis estrellable, y crida-lo» (Costa: Salamon el de la porra, I931, 5).

37. Cf. wàter-closs (Llibret en la relasió y explicasió de tot lo que conté la falla dels carrers dels Ànchels, Maldonado y Monches Servites. Añ I9I9, 6), wàter-clos (Llibret en la explicasió y relasió de tot lo que conté la falla dels carrers de La Gran Via, Pizarro y Martí. Any I9I7, 7),

38. L'alternança d'accentuació plana i aguda en aquest mot es troba també en altres textos valencians del primer terç del segle xx, ex. "És un gran chòfer» (Alberola: Terres..., I924, 50), "y el pobre chòfer» (Barchino: El pardalot de San Chuan, 1928, I2), "Aixina me hu contà el chòfer al recobrar el coneiximent" (Barchino: La forastera, I93I, II), "Quin chòfer més deshonrat!" (Comes: L’hora de la siesta, I93I, 20), "fa una arrancà de les seues i atropella més qu-un chòfer de acadèmia» (Quevedo: El vichilant de la plaseta, 1934, 4), "alguns chofers» (Alfonso: A pas de chagant, 1926, II), "tornant-lo el millor chofer» (Pensat i fet, 1929, 29), rimant amb ser; "o que.ls jafe algun jofer» (Falla de la plassa de San Francés, 1925, I2), rimant amb gent; més rares les var. chofero: "¿Tu què saps? ¿Portar un auto? ¡Fes-te chofero!» (Martí Orberà: Chent..., 55), chaufer: "Y és tot un señor «chaufer» / don Arturo" (Alberola: Ans que tot, mare, I928, 9), entre cometes en el text i rimant amb «estrellem», i chaufero: «Me despachares tu pa festechar en el chaufero aquell que sempre anaba fen-te carantoñes» (Casinos: jAra eres mare!, I926, I6), en boca del llaurador Nofre. En el DCVB i el DECat només es registra la forma aguda xofer, però Barri (I999: 535-536) recull xofer i xòfer, i fins i tot xàufer, que sentim també en val. 
car rima amb gol i amb dijous, ${ }^{39}$ i el der. futboliste, com a adj.: "desfilen les capitanes dels clubs futbolistes valensians» (íd., 7), i subst., fem. futbolista 'jugadora de futbol' (Falla del carrer de la Pas..., 2). ${ }^{40}$ Hernández Casajuana empra també la var. furgol (Traca-trac, 7), ${ }^{41}$ i el der. furgolera 'jugadora de futbol' (íd., 7), ${ }^{42}$ amb una coda sil.làbica amb -r (fur), més natural en cat., i amb la terminació analògica -gol.

El mot es va intentar adoptar al cat. en la forma football (i foot ball, foot-ball), més fidel a l'ang. football, com en altres llengües romàniques (fr. i it. football). El documentem des de I899, en La Veu de Catalunya (I899, n. I30, I; n. I43, 3). En els llibrets de falla valencians el trobem l'any 1908 amb els dos elements del compost dissociats, en una falla que critica l'arribada dels esports estrangers: "res de foots y balls, / y laus tenis y atres llandas» (Sermó que en uns cuants de desatinos y un grapat de consells fins els dedica a alguns vehins del carrer de Arrancapinos un retor que vol guardar el incògnit. Falla de l'añ I908, 7); en aquells primers temps hom relacionava humorísticament aquest manlleu (pronunciat segurament [footbá $\lambda$ ] o més aviat [fotbá $\lambda]$, [fodbá $\lambda]$ ) amb el verb fotre i amb el subst. ball, per etimologia popular: "foot-ball, y que, com el seu títul / indica, és un ball tan maula / que al que li va la pilota / [...] en la cara / el foot-ball per a huit dies» (Relasió y explicasió de tot lo que conté la falla titulada Le Grand Prix situada en los carrers de Cirilo Amorós y Pi y Margall. Añ IgIo, 2). ${ }^{43} \mathrm{La}$

39. Sovint agut en els textos val. de l'època, ex., fut-ból (amb accent gràfic sobre la «o») (Relasió y explicasió de tot lo que conté la falla de la plasa de l'Ànchel. Añ I9I3, 4), i rimant amb farol (Llibret en la relació $i$ explicació de tot lo que conté esta falla. Carrers de Colón, Xàtiva y Pi y Margall, 1922, 7) i amb vol (Pensat $i$ fet, 1924, 19), com també a Catalunya: futbol en les revistes La Veu de Catalunya (des de l'any I902, núm. I3IO, p. 3), Catalunya (I913), Cu-cut (I914), Xut (I922, n. I), entre altres. Si bé l'accentuació plana fútbol la trobem l'any I919: "gran partit de fútbol» (La Cònsola, n. 3, I7), i en els llibrets de falla val. des de i924. També es doc., encara que rarament, la forma abreviada fut 'futbol' (Llibret de la falla dels carrers de Pelayo y Bonavista. Any I923, 8, Io), anàloga al fr. foot, molt corrent en aquella llengua (cf. Rey 2006), i la var. futboll (El Borinot, 1923, n. 2, 3), i als anys 20 es troba també el der. futbolisme (Llibret de la falla dels carrers de Pelayo..., 9, Io; Llibret de la falla dels carrers Pilar y Torn, I923, 4, 5), per referir-se a la pràctica, a l'espectacle i a l'afició al futbol.

40. Masc. futboliste 'jugador de futbol' (Llibret de la falla dels carrers de l'Almudi y adyasents, I923, II; Casinos: Vidre volaor, 1926, I6), i també 'aficionat al futbol' (Vidre..., I4), en alguna ocasió en val. doc. el masc. futbolista (Llibret de la falla... de l'Almudi, II), afavorit per la rima.

4I. Cf. «anirem al fur-gol» (Vidre..., 1926, I4).

42. També es coneix a l'època futboler (Llibret en la explicasió y relasió de tot lo que conté la falla dels cantons del Mur de les Blanqueries y Pare d'Örfens. Añ I926, 5), conegut també en la premsa de Catalunya (El Borinot, I924, n. 25, 7), i futbolero 'jugador de futbol' (Pensat i fet, 1923, I2; Peris Fuentes: Poesies, 1928, 84), 'aficionat al futbol' (Llibret de falla de la plassa Canalejas. I925, I9), fem. futbolera (íd., I2), i com a adj., 'propi del futbol': «Etimologia futbolera» (íd., I8), "Chispes futboleres» (Llibret de la falla dels carrers de l'Almudi y adyasents, I923, II); i futballero 'jugador de futbol' (El seminariste, I2). En la premsa barcelonina trobem, així mateix, futbolaire: «El fútbol mateix, per això que diuen, que ha arribat al zènit del seu esclat, sospitem que va de dret cap a la decadència; i que ens perdonin els futbolaires» (El Borinot, I924, n. 6, 3).

43. Segons Coromines (DECat, Iv: 245), «de primer, la major part pronunciaven bàrbarament fudbálı; a la vista del que hem vist, probablement en val. es coneixia la realització amb $o$ en la primera síl.laba. 
Joaquim Martí Mestre

El lèxic popular valencià en la literatura de les primeres dècades del segle XX:

l'aportació de Faust Hernández Casajuana

rima sembla confirmar la pronúncia amb [á $\lambda]$ : «Als ciutadans, en els nanos / sempre ens ix pata de gall; / ara no chuen al xavo..., / iperò juen al foot-ball!» (Explicació y relació d'una falla colosal anomenada "València" $i$ que la tenim plantà des de l'horta de Ruçafa fins al portal de Serrans. A la falla valenciana de la plassa la Jordana aquest llibre dediquem, s. a. [1923], 6), «El programa és atractiu, / pués hi à músiques i ball, / i lo qu.és més sugestiu, / un gran partit de foot-ball» (Pensat y fet, I923, n. I2, I7); cf. foot-wall, rimant $\mathrm{amb}$ "radiant» $\mathrm{i}$ amb «sideral» (Llibret en la explicasió y relasió de tot lo que conté la falla de la plasa de l'Abre. Valènsia, añ I9I4, 3). També es doc. la forma amb el vocalisme reduït fotball (fot-ball) (Revista de Castellón, 63, 1914, I3; Llibret de falla. Plasa de San Bult. Añ I923, 5), i les var. fum-ball (Sendín: Tonica..., 7) i fomball (González, Bellver: El seminariste, I927, 4, 6), amb assimilació de la cons. implosiva, $\mathrm{i}$, en el primer cas, probable analogia del subst. fum. Més rares són les var. foot-bol (Llibret en la explicasió y relasió de tot lo que conté la "falla" de la plasa de San Chil. Any I923, II), amb el derivat fot-boliste, foot-boliste (íd., 9, I2), que constitueix un altre intent d'adaptació del mot, més pròxim fonèticament a l'angl. football, i foto-ball (Gayano: Del Tersio Estranjero, I92I, 7). Cf. també per aquells anys el calc peu-pilota (Pensat i fet, I927, 8), que no tingué èxit, i la perífrasi joc del baló (Llibret de la falla dels carrers de Pelayo y Bonavista. Any I923, Io), referida al mateix esport.

Altres mots relacionats amb el futbol que es troben en Hernández Casajuana són: gol (La dona fa..., 6; La vista..., Io), en sentit figurat gol 'coit' (La pandilla, 20), i la loc. fer gol en la cara (a algú) 'pegar-li una bufetada' (Valènsia a la garson, I4), cf. no fer gol (en algú) 'no casar-s'hi' (Àngeles: Al treballaor, faena, 1926, 27), ficar gol (a una dona) 'mantenir-hi relacions sexuals' (Llibret en la relasió y explicasió de tot lo que conté esta falla. Carrers de Colón, Xàtiva y Pi y Margall. Añ I923, 4); a l'època també es doc. la var. no adaptada goal (angl. goal), rimant amb colossal: «De una patà colosal, / un juaor de calbot, / al voler marcar un goal, / li arranca el cap a un ninot» (Pensat $i$ fet, I923, I7), o amb "guardant» i "pitar» (Llibret de la falla dels carrers de l'Almudi y adyasents, 1923, 7); ${ }^{44}$ córner (La pandilla..., 20), penalty (La pandilla, 20) i xut (chut) (La dona fa..., 6; La Marselina, Io), escrit també amb sch, "Eixe fa schut i goal» (Llibret de la falla dels carrers de Pelayo y Bonavista. Any I923, 7), reproduint segurament la fricativa de l'anglés shoot, i en la forma gràfica més pròxima a l'angl. shoot (i el verb shootar): "en Casellas shootava de debò, mes llurs shoots no eren de resultat positiu» (Cu-cut, I9I4, n. 2I, 219), anàloga al fr. shoot.

44. Però en: «se n'ha anat Franco en un vol / [...] i en Amèrica ha fet goal» (Esplicació i relació de tot lo que conté la falla de l'antiga plasa de San Francés, 1926, 37) goal té només realitat ortogràfica, però no fonètica. 


\section{CLOENDA}

Convé destacar la riquesa lèxica d'Hernández Casajuana, i d'altres dramaturgs valencians contemporanis, molt poc tinguts en compte pels lexicògrafs, però l'obra dels quals és imprescindible per a completar la història del lèxic català. L'estudi d'alguns dels mots usats per Faust Hernández ens ha permés aportar novetats respecte als grans diccionaris històrics i etimològics, cas de blavet, bufanúvols, mante, mec, miconina, carquinyolar, malbé, potim i empotimar, puf, entre altres. Finalment, es comprova que l'obra d'Hernández Casajuana i d'altres autors i textos populars contemporanis és una font molt valuosa per a l'estudi dels neologismes, que comencen a introduir-se a principis del segle Xx i finals del xIx, lligats a la moda i als nous costums socials, i permet resseguir les primeres passes històriques en català d'aquests mots, com hem pogut verificar amb cert detall especialment amb futbol i amb altres termes d'aquest esport.

Joaquim Martí Mestre Universitat de València joaquin.marti@uv.es

\section{REFERÈNCIES BIBLIOGRÀFIQUES}

Almela Pérez, Ramón (1999) Procedimientos de formación de palabras en español, Barcelona, Ariel.

Andolz, Rafael (2004) Diccionario aragonés, Saragossa, Mira.

BARRI, Montserrat (1999) Aportació a l'estudi dels gal.licismes del català, Barcelona, IEC. Beltran, Vicent (2005) El parlar de la Marina Alta, Alacant, Universitat d'Alacant. Beltran, Joan S. (20Io) Vocabulari de cruïlla, Benicarló, Onada.

Besses, Luis (1905) Diccionario de argot español, Barcelona, Soler.

Colomina, Jordi (I99I) Elvalencià de la Marina Baixa, València, Generalitat Valenciana. $D A g=$ Diccionari Aguiló (1917-1934) Barcelona, IEC, 8 toms.

DCVB = Alcover, Antoni M. \& Francesc de B. Moll (1988) Diccionari catalàvalencià-balear, Palma de Mallorca, Moll, io vol.

$D C E C H$ = Coromines, Joan, amb la col-laboració de José A. Pascual (2000-2002)

Diccionario crítico etimológico castellano e hispánico, Madrid, Gredos, 6 vol.

DECat = Coromines, Joan (1980-2002) Diccionari etimològic i complementari de la llengua catalana, Barcelona, Curial, io vol. 
Endize = NAGORE, Francho, dir. (I999) Endize de bocables de l'aragonés, Osca, Instituto de Estudios Altoaragoneses.

EscLl= EsCrig, Josep \& Constantí Llombart (I887) Diccionario valenciano-castellano, València, P. Aguilar.

FajARnés, Enric (2000) Recull de dites i refranys d'Eivissa, Eivissa, IEE.

Giner, Joan (20I3) El valencià de la Valldigna, València, Universitat de València.

Giralt, Javier (2005) Lèxic de la Llitera, Lleida, Milenio.

López del Castillo, Lluís (2002) Diccionari de formació de paraules, Barcelona, Edicions 62.

MarTí, Joaquim (2006) Diccionari històric del valencià col-loquial, València, Universitat de València.

- (20II) Diccionari de Josep Bernat i Baldoví, València, Denes.

Martí Gadea, Joaquim (I906) Tipos, modismes y coses rares y curioses de la terra del $G \grave{e} . . .$, València, Antonio López.

MGad = MARTí GADEA, Joaquim (I89I) Diccionario general valenciano-castellano, València, Canales Romà.

Pomares, Joaquim (I997) Diccionaridel català popular i d'argot, Barcelona, Edicions 62.

Rey, Alain, dir. (2006) Dictionnaire historique de la langue française, París, Le Robert. Riera-Eures, Manel \& Margarida Sanjaume (2002) Diccionari d'onomatopeies i mots de creació expressiva, Barcelona, Edicions 62.

Rull, Xavier (2004) La formació de mots, Barcelona, Eumo.

SAlvador, Carles (I943) «Petit vocabulari de Benassal (Maestrat)», dins Miscel-lània Fabra, Buenos Aires, pp. 242-263.

SÁnchez, Antonio, Rafel Taixés \& Rafael TAsis (I99i) Argot barceloní, Barcelona, Parsifal.

SAnMartín, Júlia (I997) «El caló com a sociolecte teatral. De Juli Vallmitjana a Faust Hernández Casajuana», dins F. Carbó, R. Rosselló \& J. L. Sirera (eds.), Escalante $i$ el teatre del segle XIX, València/Barcelona, IIFV/PAM, pp. 333-346.

Segura, Josep Carles (2003) Una cruïlla lingüistica. Caracterització del parlar del Baix Vinalopó, Alacant, Universitat d'Alacant.

Sirera, Josep L. \& Rodolf Sirera, eds. (I993) Faust Hernández Casajuana, Teatre, València, IVEI.

VeNY, Joan (200I) Llengua i entorn natural, Barcelona, Edicions 62.

WAGNer, Max-L. (I924) Notes linguistiques sur l'argot barcelonais, Barcelona, IEC. ZARAGOZÀ, Marina (1982) El cultiu tradicional de l'arròs a Silla, València, IFV. 